\title{
Synthesis and characterization of isoprene oligomers to compare different production chemical processes
}

\author{
Renata Vieira Pires ${ }^{1}$, Larissa Mota Barros Pessoa ${ }^{1}$, Monica de Almeida de Sant'Anna', \\ Alexander Fainleib ${ }^{1,2}$, Rita de Cassia Pessanha Nunes ${ }^{3}$ and Elizabete Fernandes Lucas ${ }^{1,3 *}$
}

\begin{abstract}
${ }^{1}$ Laboratório de Macromoléculas e Colóides na Indústria de Petróleo - LMCP, Instituto de Macromoléculas Professora Eloisa Mano - IMA, Universidade Federal do Rio de Janeiro - UFRJ, Rio de Janeiro, RJ, Brasil ${ }^{2}$ Institute of Macromolecular Chemistry - IMC, The National Academy of Sciences of Ukraine - NAS, Kyiv, Ukraine

${ }^{3}$ Programa de Pós-graduação em Engenharia Metalúrgica e de Materiais - PEMM, Instituto Alberto Luiz Coimbra de Pós-graduação e Pesquisa de Engenharia - COPPE, Universidade Federal do Rio de Janeiro - UFRJ, Rio de Janeiro, RJ, Brasil

*elucas@metalmat.ufrj.br
\end{abstract}

\begin{abstract}
Three methods to obtain isoprene oligomers were evaluated: chemical degradation of non-vulcanized coagulated natural rubber; chemical degradation of natural rubber latex; and oligomerization of the isoprene monomer. The products were characterized by infrared spectrometry (FTIR), nuclear magnetic resonance (NMR) and size-exclusion chromatography (SEC). All the three processes were efficient and can be controlled in order to obtain products with desired molar mass. Among the degradation processes, the reaction with the non-vulcanized rubber led to the purest products, but this process has the disadvantage of relatively higher catalyst cost of the catalyst. Reactions of isoprene with free radical initiation produced oligomers under specific conditions: low isoprene concentration, low initiator concentration, and xylene as solvent. The results discussed here allows the readers to have a chemistry overview and experimental insights about different chemical routes to obtain isoprene oligomers, compiled together in the same work. It shall be helpful for applied chemistry researches.
\end{abstract}

Keywords: natural rubber, degradation, synthesis, isoprene oligomers.

How to cite: Pires, R. V., Pessoa, L. M. B., Sant'Anna, M. A., Fainleib, A., Nunes, R. C. P., \& Lucas, E. F. (2019). Synthesis and characterization of isoprene oligomers to compare different production chemical processes. Polimeros: Ciência e Tecnologia, 29(1), e2019015. https://doi.org/10.1590/0104-1428.04418

\section{Introduction}

The use of products from the degradation of natural rubber (cis-polyisoprenes) has been widely studied for various application areas, because natural rubber is a renewable source resource and a potential raw material for various oligomers. These oligomers can be employed in formulations to modify polymers, to obtain polyelectrolytes, as artificial skin, among others ${ }^{[1-3]}$.

Natural rubber, poly(cis-1,4-isoprene), is obtained from various trees that produce rubber latex, such as Hevea Brasiliensis. Latex is a polydisperse colloidal system of rubber particles in aqueous phase. The rubber produced from the latex has molar mass in the range of 50,000 to $3,000,000(\mathrm{~g} / \mathrm{mol})^{[4-6]}$. The depolymerization and degradation of natural rubber include the following main methods: (i) metathesis reactions with chain transfer agents, a transition metal complex (organometallic catalysts); (ii) oxidative degradation through epoxidation with hydrogen peroxide, periodic acid, m-chloroperbenzoic acid, $\mathrm{NaNO}_{2},\left(\mathrm{NH}_{4}\right)_{2} \mathrm{~S}_{2} \mathrm{O}_{8}$, $\mathrm{K}_{2} \mathrm{~S}_{2} \mathrm{O}_{8}$ /sodium dodecyl sulfate, microorganisms, iron (II) chloride/phenylhydrazine or iron(III) chloride/chloranil

systems, diallyl disulfide etc., and (iii) using sunlight, ultraviolet radiation or ultrasound ${ }^{[7-10]}$. All studies found in the literature, about chemical reactions and rubber and its derivate structures and properties, are more focused in describing separately natural rubber degradation methods and respective chemistry characterization.

The methods described enable obtaining isoprene oligomers from natural rubber. However, they can also be obtained from polymerization of isoprene. Isoprene is a conjugated diene, so it is able to produce a polymerization reaction through the use of different initiators, such as free radical, anionic, cationic and coordination initiators. Distinct isomeric structures can be produced, depending on the initiation system used. The obtainment of the oligomer can be facilitated by the use of chain transfer agents such as dodecyl mercaptan ${ }^{[1,12]}$.

To compare the isoprene oligomers obtained with different reagents and processes, in this work these oligomers were obtained by oligomerization of isoprene and chemical degradation of (i) natural rubber latex and 
(ii) coagulated non-vulcanized natural rubber. All the products were characterized by Fourier-transform infrared spectrometry (FTIR), nuclear magnetic resonance spectrometry (NMR) and size-exclusion chromatography (SEC). The aim of this work was somehow to facilitate the readers that may have interest in the obtention of isoprene oligomers, by providing some insights and comparison of three different chemical methods described together in the same academic source.

\section{Materials and Methods}

\subsection{Methods to obtain the polyisoprene oligomers}

The polyisoprene oligomer samples were obtained by three chemical routes: chemical degradation of non-vulcanized coagulated natural rubber; chemical degradation of natural rubber latex; and oligomerization of isoprene.

\subsubsection{Chemical degradation of coagulated non-vulcanized natural rubber}

The degradation of coagulated non-vulcanized natural rubber (NR) consisted of a metathesis reaction, i.e., a catalytically induced reaction in which the carbon-carbon double bonds undergo cleavage and reformulation processes ${ }^{[13-16]}$. The reaction was performed with small pieces of NR (Braslatex Ind. Com. de Borrachas Ltda.), a second-generation catalyst based on Ru-alkylidene (second-generation Hoveyda-Grubbs, 97\% - Sigma-Aldrich), dissolved in dichloromethane (Vetec Química Fina Ltda.), and $\beta$-pinene (Sigma-Aldrich) as transfer agent, at temperatures ranging from 30 to $45^{\circ} \mathrm{C}$, in a nitrogen atmosphere with magnetic stirring ${ }^{[14]}$. Molar ratios of NR: $\beta$-pinene varying from 3:1 to $1: 1$ and of NR:catalyst (NR:Grubbs) ranging from 50:1 to 1000:1 were used. After 48 hours, the reaction was stopped with ethyl vinyl ether (Sigma-Aldrich) and the final product was left for 72 hours in a vacuum oven at temperature of approximately $30{ }^{\circ} \mathrm{C}$ to remove the dichloromethane.

\subsubsection{Chemical degradation of the natural rubber latex}

First, the natural rubber latex (Braslatex Ind. Com. de Borrachas Ltda.) was submitted to an epoxidation reaction followed by procedures described in the literature ${ }^{[17-19]}$. The latex was kept under magnetic stirring in an open system for about 4 hours at room temperature to eliminate ammonia. Then, $5 \%$ of the stabilizer Ultranex (Oxiteno Nordeste S.A.) ( $\%$ by mass, in relation to the dry mass of natural rubber) was added and the stirring was maintained for another 30 minutes, followed by 12 hours of rest. The epoxidation reaction was conducted through slowly addition of formic acid (Vetec Química Fina Ltda.) and hydrogen peroxide (Vetec Química Fina Ltda.), at NR: $\mathrm{HCOOH}$ or $\mathrm{NR}: \mathrm{H}_{2} \mathrm{O}_{2}$ molar ratios of $1: 0.2$ or $1: 0.4$, at $60^{\circ} \mathrm{C}$.

The degradation reaction of the epoxidized NR occurred in a closed system at temperatures of 30,45 and $60{ }^{\circ} \mathrm{C}$, in the presence of periodic acid $\left(\mathrm{H}_{5} \mathrm{IO}_{6}\right)$ (Vetec Química Fina.) at a $\mathrm{NR}_{\text {dry/epoxidized }}: \mathrm{H}_{5} \mathrm{IO}_{6}$ molar ratio that varied from $1: 1$ to $1: 3.75$. After the reaction, the product was dried in a vaccum oven at $30^{\circ} \mathrm{C}$, over a period of 72 hours.

\subsubsection{Oligomerization of isoprene}

The oligomerization was carried out with isoprene (Lanxess Energizing Chemistry) distilled at $34{ }^{\circ} \mathrm{C}$. The reactions were conducted with two types of initiation: anionic, using butyllithium (Sigma-Aldrich); and free radical, employing benzoyl peroxide (Vetec Química Fina Ltda.). The anionic polymerizations were carried out by the mass technique, using isoprene:butyllithium molar ratios of 1:0.04 and 1:0.16, varying the reaction temperature from 25 to $30^{\circ} \mathrm{C}$. The free radical polymerizations were performed in a toluene or xylene solution with isoprene:benzoyl peroxide molar ratios of 1:0.1, 1:0.3 and 1:0.5. The free radical reactions performed in the presence of the transfer agent utilized dodecyl-mercaptan (Merck), at a temperature of about $80^{\circ} \mathrm{C}$. After the reaction, the product was placed in a vacuum oven at approximately $35^{\circ} \mathrm{C}$ to remove the residual monomer, until reaching constant weight (at least 72 hours).

\subsection{Characterization of the oligomers}

The reaction products were characterized by Fouriertransform infrared spectroscopy (FTIR), nuclear magnetic resonance spectroscopy (NMR) and size-exclusion chromatography (SEC).

The FTIR analyses were carried out with a Varian Excalibur 3100 spectrometer, using casting film over a $\mathrm{KBr}$ window, with scan from 4000 to $600 \mathrm{~cm}^{-1}$ and 20 acquisitions with resolution of $4 \mathrm{~cm}^{-1}$.

Some reaction products were characterized by carbon nuclear magnetic resonance $\left(\mathrm{C}^{13} \mathrm{NMR}\right)$, with frequency of $75 \mathrm{MHz}$ and sample concentration of approximately $5 \%$ in deuterated chloroform (Cambridge Isotope Laboratories, Inc.). The epoxidation reaction products were characterized by hydrogen nuclear magnetic resonance $\left(\mathrm{H}^{1} \mathrm{NMR}\right)$ at concentration of $2 \%$ in deuterated chloroform. The molar percentage of the epoxidized natural rubber was calculated according to the method described in the literature ${ }^{[18]}$, by relating the areas under the peaks referring to the olefinic protons present in the structure of the residual cis-1,4-polyisoprene (1), at $5.1 \mathrm{ppm}$, and the protons adjacent to the oxygen of the epoxidized ring (2), at $2.7 \mathrm{ppm}$ (Equation 1 and Figure 1).

Epoxidation degree $=$ Area $_{2.7} /\left(\right.$ Area $_{2.7}+$ Area $\left._{5.1}\right) \times 100$

The product samples had the average molar mass measured by size-exclusion chromatography (SEC) using a Viscotek GPC Max VE 2005 chromatograph with a Shodex KF 806M column. The samples were dissolved in chromatographic-grade tetrahydrofuran (Vetec Química Fina Ltda.) at $10 \mathrm{mg} / \mathrm{mL}$ and filtered through a Chromafil PTFE membrane with pore size of $0.45 \mu \mathrm{m}$.

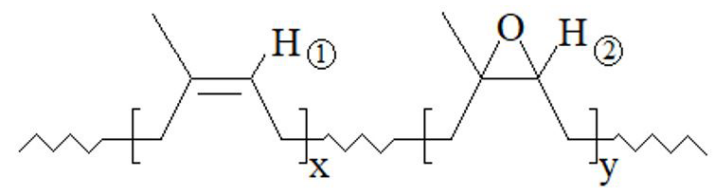

Figure 1. Polyisoprene expected structure after epoxidation reaction. 


\section{Results and Discussion}

\subsection{Degradation products of the non-vulcanized natural rubber}

The products obtained from the degradation reaction of non-vulcanized natural rubber were identified as follows: R\#-NR: reaction product $(\mathrm{R})$ from degradation of coagulated non-vulcanized natural rubber (NR), where \# corresponds to the reaction sequence number. The concentrations of the ruthenium-based catalyst and transfer agent, $\beta$-pinene, were varied, aiming to reduce the molar mass of the products. Table 1 identifies the products and the average molar mass results.

Unexpectedly, the average molar mass values obtained for the degradation products of coagulated NR were not coherent with the variation of the reaction conditions, i.e., they were not in line with the NR:catalyst and NR:transfer agent ratios, representing a difficult reaction control.

The FTIR spectra of the coagulated natural rubber degradation products were similar with each other and also similar to the spectrum of the natural rubber before degradation. This result was expected, since all the products were obtained using the same degradation methods, only varying the concentrations of the catalyst and transfer agent. The FTIR spectrum referring to the product R12-NR, presented as an example in Figure 2a, indicates the characteristic absorption frequencies of the organic groups present in natural rubber, including the vibration due to the $\mathrm{C}-\mathrm{H}$ out-of-plane angular deformation of the polyisoprene with cis isomerism, at approximately $840 \mathrm{~cm}^{-1}$. Only the products R5-NR to R9-NR presented two deformation bands in this region: one at $840 \mathrm{~cm}^{-1}(\mathrm{~A})$ and the other at $880 \mathrm{~cm}^{-1}(\mathrm{~B})$, as shown in Figure 2b. The latter band can be attributed to the presence of residual $\beta$-pinene, which also was identified in the spectrum of $\beta$-pinene.

Figures $3 \mathrm{a}$ and $3 \mathrm{~b}$ present, respectively, the ${ }^{13} \mathrm{C}-\mathrm{NMR}$ and ${ }^{1 \mathrm{H}}$-NMR spectra of the product R5-NR. All the products characterized presented similar spectra, with the predominant presence of polyisoprene (PI) and residual $\beta$-pinene. Total similarity can be observed with the natural rubber spectrum, indicating that the chemical degradation process led only to obtaining the structure of polyisoprene, since no chemical shifts were identified characteristic of the presence of the terminal terpene in the PI's structure, as also found by other researchers for similar reaction $S^{[14]}$. Polyisoprene oligomers without terminal terpene structures can be more suitable for some specific applications. The signals identified from A to $\mathrm{J}$ refer to the residual $\beta$-pinene not incorporated in the PI's structure $^{[20]}$, which was confirmed in the spectrum obtained with the ATP technique. The ${ }^{1} \mathrm{H}-\mathrm{NMR}$ spectrum presented in Figure $3 \mathrm{~b}$ also indicates the presence of hydrogens characteristic of polyisoprene and $\beta$-pinene.

The molar percentage of $\beta$-pinene in relation to polyisoprene was calculated based on the proportion between the areas at $5.10 \mathrm{ppm}$ and $4.60 \mathrm{ppm}$ (doublet), related to the $\mathrm{H}$ of the secondary olefinic carbon of the PI and the $2 \mathrm{H}$ of the olefinic

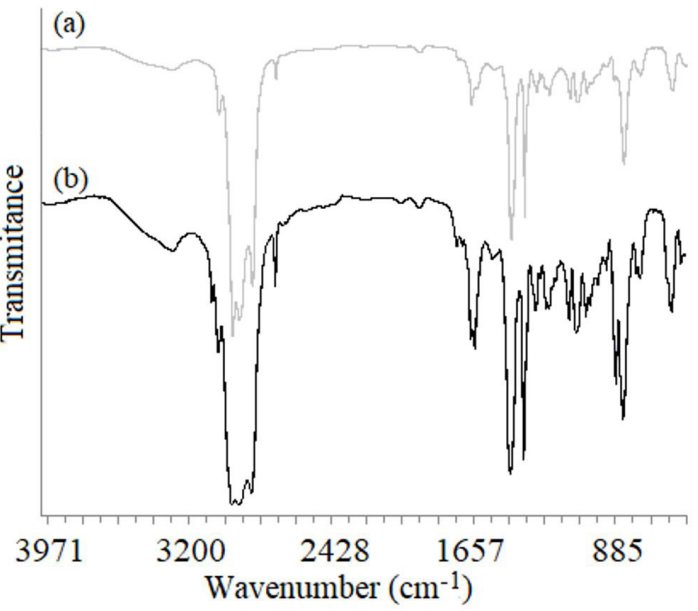

Figure 2. Infrared spectra of the non-vulcanized coagulated NR degradation products: (a) R12-NR and (b) R5-NR.

Table 1. Average molar masses of non-vulcanized coagulated NR degradation products, obtained after $48 \mathrm{~h}$ of reaction at $30^{\circ} \mathrm{C}$.

\begin{tabular}{lcccccc}
\hline Product & $\begin{array}{c}\text { Ratio NR: } \\
\boldsymbol{\beta} \text {-pinene } \\
\text { mol:mol }\end{array}$ & $\begin{array}{c}\text { Ratio } \\
\text { NR:Grubbs } \\
\text { mol:mol }\end{array}$ & $\overline{\boldsymbol{M}}_{\boldsymbol{p}}$ & $\overline{\boldsymbol{M}}_{\boldsymbol{n}}$ & $\overline{\boldsymbol{M}}_{\boldsymbol{w}}$ & $\overline{\boldsymbol{M}}_{\boldsymbol{w}} / \overline{\boldsymbol{M}}_{\boldsymbol{n}}$ \\
\cline { 5 - 6 } R2-NR* & $1: 1$ & $1000: 1$ & 5,990 & 3,090 & 12,850 & 4.16 \\
R3-NR & $2: 1$ & $1000: 1$ & 2,382 & 1,034 & 6,641 & 6.42 \\
R4-NR & $3: 1$ & $1000: 1$ & 3,140 & 2,179 & 10,149 & 4.66 \\
R5-NR & $1: 1$ & $500: 1$ & - & 29,500 & 64,228 & 2.17 \\
R6-NR & $2: 1$ & $500: 1$ & 11,942 & 7,075 & 13,526 & 1.35 \\
R9-NR** & $1: 1$ & $200: 1$ & 2,772 & 1,341 & 2,886 & 2.14 \\
R8-NR** & $2: 1$ & $200: 1$ & 1,311 & 979 & 1,505 & 1.54 \\
R7-NR** & $3: 1$ & $200: 1$ & 1,052 & 1,324 & 1,689 & 1.28 \\
R12-NR & $1: 1$ & $200: 1$ & 46,156 & 28,064 & 51,265 & 1.83 \\
R11-NR & $2: 1$ & $200: 1$ & 6,127 & 2,230 & 6,601 & 2.96 \\
R10-NR & $3: 1$ & $200: 1$ & 7,980 & 3,094 & 8,313 & 2.69 \\
R13-NR & $1: 1$ & $100: 1$ & 6,861 & 2,647 & 7,072 & 2.67 \\
R14-NR & $2: 1$ & $100: 1$ & 12,505 & 9,383 & 14,245 & 1.52 \\
R15-NR & $1: 1$ & $50: 1$ & 8,577 & 6,326 & 9,591 & 1.52 \\
\hline
\end{tabular}

*Reaction of 72 hours; **Reaction at $45^{\circ} \mathrm{C} ; \bar{M}_{p}=$ molar mass at the peak of the molar mass distribution curve; $\bar{M}_{n}=$ number average molar mass; $\bar{M}_{w}=$ weight average molar mass 
$\mathrm{CH}_{2}$ of the $\beta$-pinene, respectively. The molar percentages calculated for the free b-pinene were $30,9,9,7$ and $32 \%$, respectively, for samples R5-NR, R6-NR, R7-NR, R11-NR and R12-NR. These values are coherent with the proportion of NR: $\beta$-pinene utilized in the reaction.

The more subtle peaks, indicated by the arrow in Figure $3 \mathrm{~b}$, suggest the presence of other different compounds of PI and $\beta$-pinene, probably the result of side reactions specific to self-metathesis or isomerization of the $\beta$-pinene. Another study reported that the terminal olefin metathesis is followed by the methyl groups exchange and that this reaction occurs substantially faster than the metathesis reactions of olefins with double internal bonds ${ }^{[14]}$. These peaks were identified in the spectra obtained for some other NR degradation products, but with different intensities than those observed in the spectrum of R5-NR.

\subsection{Degradation products of the natural rubber latex}

The NR latex was first epoxidized and the products of this reaction were characterized by FTIR and ${ }^{1} \mathrm{H}-\mathrm{NMR}$. The FTIR spectra revealed the formation of epoxidized isoprene units, by the presence of the bands in the $800-900 \mathrm{~cm}^{-1}$ and $1200-1300 \mathrm{~cm}^{-1}$ regions, which are characteristic of the asymmetric and symmetric axial deformation of the

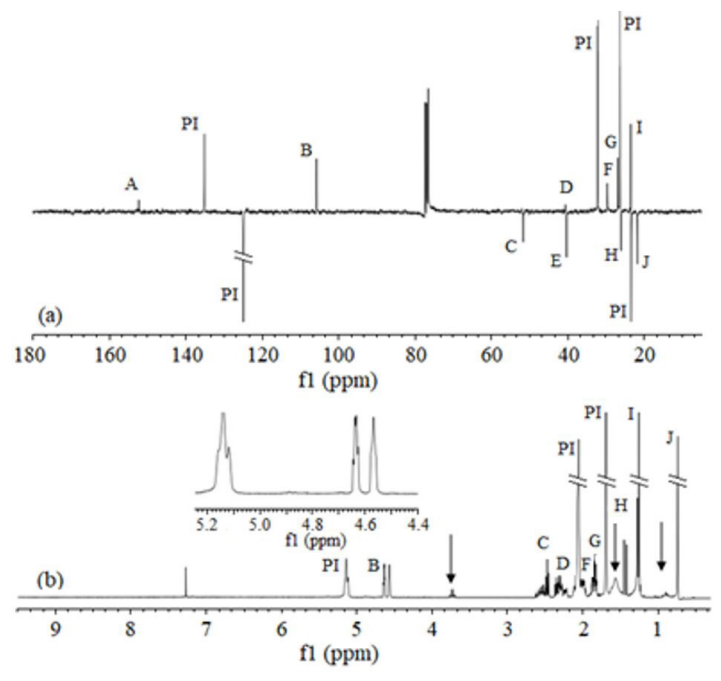

Figure 3. ${ }^{13} \mathrm{C}-\mathrm{NMR}$ (a) and ${ }^{1} \mathrm{H}-\mathrm{NMR}$ (b) spectra of R5-NR product, obtained from non-vulcanized coagulated NR degradation. epoxide ring, respectively. The continuing presence of the band near $1670 \mathrm{~cm}^{-1}$, related to the axial deformation of the $\mathrm{C}=\mathrm{C}$ bond, representative of the isoprene unit, indicates the epoxidation reaction did not attain $100 \%$ yield.

The content of the epoxy groups in the latex, which served as the base for calculating the quantity of the oxidative degradation agent (periodic acid) used in the degradation reactions, was determined by ${ }^{1} \mathrm{H}-\mathrm{NMR}$. Table 2 presents the epoxidation reaction conditions and epoxidation degree values obtained from Equation 1 (Figure 1).

In general, the epoxidized materials had epoxidation levels between 10 and $20 \%$ for the same reaction conditions (1:0.2 for $\mathrm{NR}: \mathrm{HCOOH}$ and $\mathrm{NR}: \mathrm{H}_{2} \mathrm{O}_{2}, 8$ hours of reaction). The epoxidation level increased with storage time before using the samples in the degradation reaction. For example, the epoxidation level of reaction \#4 increased from 5 to $11 \%$ (4E) and for reaction \#5 it rose from 12 to $19 \%$ (5E). A kinetic study showed that the epoxidation degree increased until a reaction time of 48 yours, after which it remained practically constant. The reactions conducted for equal times (8E, 9E and $10 \mathrm{E}$ ) or longer (6E) than 48 hours reached levels of about $28 \%$ (Table 2).

All the epoxidized products were submitted to the degradation reaction and identified as $\mathrm{R} \# \mathrm{D}(\# \mathrm{E})$, where $\mathrm{R} \# \mathrm{D}$ represents the product of the degradation reaction after the epoxidation reaction of the latex (\#E). Table 3 reports the degradation reaction of the epoxidized products and average molar masses obtained. The average molar mass results were coherent with the reaction conditions used. Lower molar masses were obtained in the following conditions: (i) higher epoxidation degrees of the samples (e.g., comparing R5D to R9D and R15D to R17D); (ii) greater amount in excess of $\mathrm{H}_{5} \mathrm{IO}_{6}$ in relation to the epoxidized NR (e.g., comparing R1D to R3D and R4D, and R5D and R14D to R15D); (iii) longer degradation times (e.g., comparing R3D to R4D, R6D to R7D, and R14D to R11D). The degradation reactions conducted at $60{ }^{\circ} \mathrm{C}$ seemed to be less efficient. Among the products obtained under comparable conditions (R5D, R6D, R7D, R8D and R9D), the temperature appeared to have a stronger influence on molar mass than did the degradation time.

In all the FTIR spectra, the relation between the bands referring to $\mathrm{C}=\mathrm{C}\left(\sim 1670 \mathrm{~cm}^{-1}\right)$, the epoxide ring $\left(\sim 850 \mathrm{~cm}^{-1}\right)$ and $\mathrm{C}=\mathrm{O}\left(\sim 1720 \mathrm{~cm}^{-1}\right)$ showed reduced intensities of the oxirane and $\mathrm{C}=\mathrm{C}$ bands in the degraded product, in respecting to an increase of the $\mathrm{C}=\mathrm{O}$ band, which confirms the degradation

Table 2. Reaction conditions and respective epoxidation degrees.

\begin{tabular}{cccccc}
\hline $\begin{array}{c}\text { Sample } \\
\#\end{array}$ & $\begin{array}{c}\mathbf{N R}_{\text {dry }}: \mathbf{H C O O H} \\
(\mathbf{m o l} / \mathbf{m o l})\end{array}$ & $\begin{array}{c}\mathbf{N R}_{\text {dry }}: \mathbf{H}_{2} \mathbf{O}_{2} \\
(\mathbf{m o l} / \mathbf{m o l})\end{array}$ & $\begin{array}{c}\text { Temperature } \\
\left({ }^{\mathbf{C}} \mathbf{C}\right)\end{array}$ & $\begin{array}{c}\text { Time } \\
(\mathbf{h})\end{array}$ & $\begin{array}{c}\text { Epoxidation degree } \\
(\mathbf{\%})\end{array}$ \\
\hline $1 \mathrm{E}$ & $1: 0.2$ & $1: 0.2$ & 60 & 8 & 14 \\
$2 \mathrm{E}$ & $1: 0.2$ & $1: 0.2$ & 60 & 8 & 16 \\
$3 \mathrm{E}$ & $1: 0.2$ & $1: 0.2$ & 60 & 8 & 10 \\
$4 \mathrm{E}$ & $1: 0.2$ & $1: 0.2$ & 60 & 8 & 11 \\
$5 \mathrm{E}$ & $1: 0.2$ & $1: 0.2$ & 60 & 8 & 31 \\
$6 \mathrm{E}$ & $1: 0.2$ & $1: 0.2$ & 60 & 72 & 29 \\
$8 \mathrm{E}$ & $1: 0.4$ & $1: 0.2$ & 60 & 48 & 26 \\
9E & $1: 0.2$ & $1: 0.4$ & 60 & 48 & 29 \\
$10 \mathrm{E}$ & $1: 0.4$ & $1: 0.4$ & 60 & 48 & \\
\hline
\end{tabular}


reaction. The intensity reduction of the band refered to the epoxide ring depends on the epoxidation condition, resulting in different degradation degrees, as exemplified by FTIR spectra of the degraded samples R1D(1E) and R6D(3E) depicted in Figure 4.

The comparison of R1D(1E) spectrum of Figure 4 with the spectrum of the epoxidized latex $1 \mathrm{E}$ shows the continued presence of the epoxide group ( $~ 850$ and $\left.1250 \mathrm{~cm}^{-1}\right)$, even after the degradation reaction, although with lower intensity, as expected. The appearance of a pronounced band at $1720 \mathrm{~cm}^{-1}$ and the significant increase in the intensity and better definition of the band at $3430 \mathrm{~cm}^{-1}$ indicate the presence of carbonyl groups and hydroxyl, respectively, which were present at the end of the degraded polyisoprene chains. The various absorption bands present at lower wavelengths (1100 to $1200 \mathrm{~cm}^{-1}$ and 600 to $800 \mathrm{~cm}^{-1}$ ) can be attributed to the residual periodic acid. The products $\mathrm{R} 6 \mathrm{D}(3 \mathrm{E})$ and $\mathrm{R} 7 \mathrm{D}(3 \mathrm{E})$, both from the degradation reaction of the latex with $10 \%$ epoxidation conducted at $60^{\circ} \mathrm{C}$, presented practically no difference between the intensities corresponding to the carbonyl and terminal hydroxyl groups in relation to the $\mathrm{C}=\mathrm{C}$ group of the isoprene unit, and in relation to the characteristic bands of the epoxide ring, disregardless of the concentration of periodic acid utilized. This result suggests low efficiency of the degradation reaction in the conditions analyzed, and is concordant with the much higher molar mass values obtained for these products (Table 3 ).

The FTIR spectra of the products $\mathrm{R} 5 \mathrm{D}(2 \mathrm{E}), \mathrm{R} 14 \mathrm{D}(8 \mathrm{E})$ and R16D(9E) (Figure 5), obtained under the same degradation conditions, i.e., $\mathrm{NR}: \mathrm{H}_{5} \mathrm{IO}_{6}$ ratio of $1: 1.25$, temperature of $30{ }^{\circ} \mathrm{C}$ and 24 hours of reaction, revealed that the ratio between the intensities related to the carbonyl/hydroxyl ratio and the $\mathrm{C}=\mathrm{C}$ group of the isoprene unit did not follow

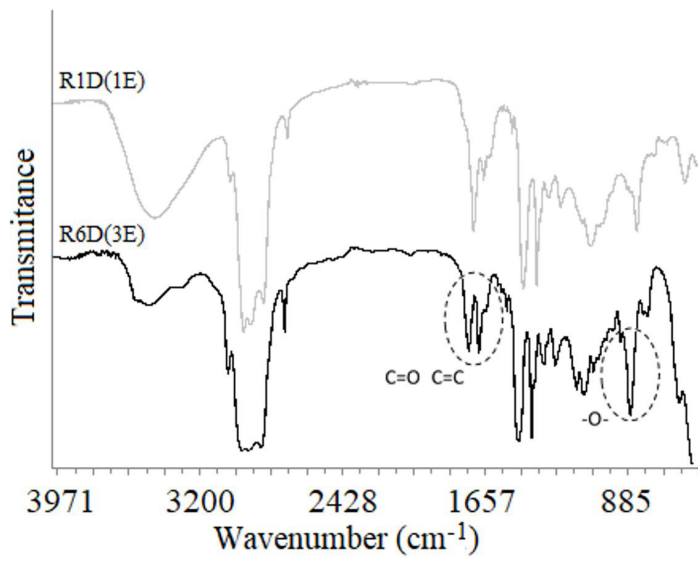

Figure 4. FTIR spectra of R1D(1E) and R6D(3E) products.

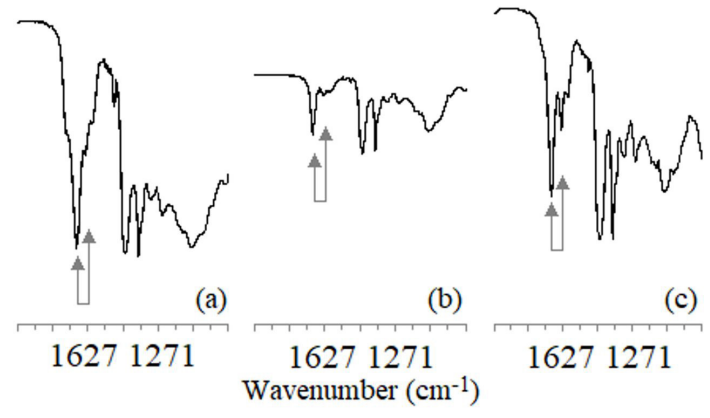

Figure 5. Infrared spectra of (a) R5D(2E), (b) R14D(8E) and (c) $\mathrm{R} 16 \mathrm{D}(9 \mathrm{E})$ products.

Table 3. Relative molar mass values of the epoxidized latex degradation products, obtained from $30(*)$ and $60(* *){ }^{\circ} \mathrm{C}$ reactions.

\begin{tabular}{|c|c|c|c|c|c|c|c|}
\hline Sample & $\mathrm{NR}_{\text {epoxidada }} \stackrel{\text { Razão }}{: \mathrm{H}_{5} \mathrm{IO}_{6}}$ & $\begin{array}{c}\text { Tempo } \\
\text { (h) }\end{array}$ & $\begin{array}{c}\text { Epoxidação } \\
(\%)\end{array}$ & $\bar{M}_{p}$ & $\bar{M}_{n(\mathrm{~g} / \mathrm{mol})}$ & $\bar{M}_{w}$ & $\bar{M}_{w} / \bar{M}_{n}$ \\
\hline R1D(1E)* & $1: 1$ & 12 & $50^{ \pm}$ & 2,745 & 2,229 & 8.058 & 3.62 \\
\hline $\mathrm{R} 2 \mathrm{D}(1 \mathrm{E})^{*}$ & $1: 1.25$ & 24 & 14 & - & - & - & - \\
\hline $\mathrm{R} 3 \mathrm{D}(2 \mathrm{E})^{*}$ & $1: 1.25$ & 12 & $25^{\mathrm{t}}$ & 3,068 & 2,739 & 11,215 & 4.09 \\
\hline $\mathrm{R} 4 \mathrm{D}(2 \mathrm{E})^{*}$ & $1: 1.25$ & 24 & $25^{\mathrm{t}}$ & 941 & 851 & 2,682 & 3.15 \\
\hline $\mathrm{R} 5 \mathrm{D}(2 \mathrm{E})^{*}$ & $1: 1.25$ & 24 & 16 & 1,969 & 2,117 & 7,292 & 3.45 \\
\hline $\mathrm{R} 6 \mathrm{D}(3 \mathrm{E}) * *$ & $1: 1.25$ & 24 & 10 & 10,647 & 4,840 & 24,169 & 4.99 \\
\hline $\mathrm{R} 7 \mathrm{D}(3 \mathrm{E}) * *$ & $1: 1.25$ & 12 & 10 & 15,217 & 14,060 & 39,059 & 2.78 \\
\hline $\mathrm{R} 8 \mathrm{D}(4 \mathrm{E})^{*}$ & $1: 1.25$ & 12 & 11 & 3,179 & 1,931 & 7,274 & 3.77 \\
\hline $\mathrm{R} 9 \mathrm{D}(4 \mathrm{E}) *$ & $1: 1.25$ & 24 & 11 & 4,000 & 3,558 & 4,084 & 1.15 \\
\hline $\mathrm{R} 10 \mathrm{D}(5 \mathrm{E})^{*}$ & $1: 2.5$ & 12 & 19 & 2,665 & 2,640 & 17,493 & 6.63 \\
\hline $\mathrm{R} 11 \mathrm{D}(6 \mathrm{E})^{*}$ & $1: 1.25$ & 12 & 32 & 5,339 & 3,453 & 16,530 & 4.79 \\
\hline $\mathrm{R} 14 \mathrm{D}(8 \mathrm{E})^{*}$ & $1: 1.25$ & 24 & 28 & 2,487 & 2,189 & 8,494 & 3.88 \\
\hline $\mathrm{R} 15 \mathrm{D}(8 \mathrm{E})^{*}$ & $1: 2.5$ & 24 & 29 & 3,850 & 2,636 & 7,573 & 2.88 \\
\hline $\mathrm{R} 16 \mathrm{D}(9 \mathrm{E}) *$ & $1: 1.25$ & 24 & 26 & 7,266 & 4,133 & 28,473 & 6.89 \\
\hline $\mathrm{R} 17 \mathrm{D}(9 \mathrm{E}) *$ & $1: 2.5$ & 24 & 26 & 6,735 & 2,565 & 13,632 & 5.31 \\
\hline $\mathrm{R} 18 \mathrm{D}(10 \mathrm{E})^{*}$ & $1: 1.25$ & 48 & 29 & 6,962 & 2,475 & 27,695 & 11.19 \\
\hline $\mathrm{R} 19 \mathrm{D}(10 \mathrm{E})^{* *}$ & $1: 1.25$ & 6 & 29 & 1,760 & 3,818 & 83,329 & 21.82 \\
\hline $\mathrm{R} 20 \mathrm{D}(10 \mathrm{E}) *$ & $1: 2.25$ & 48 & 29 & 6,455 & 2,183 & 25,196 & 11.54 \\
\hline $\mathrm{R} 21 \mathrm{D}(10 \mathrm{E})^{* *}$ & $1: 2.25$ & 6 & 29 & 14,454 & 14,553 & 19,504 & 1.34 \\
\hline $\mathrm{R} 22 \mathrm{D}(10 \mathrm{E}) *$ & $1: 3.75$ & 48 & 29 & 2,478 & 2,586 & 11,439 & 4.42 \\
\hline
\end{tabular}

$\bar{M}_{p}=$ molar mass at the peak of molar mass distribution curve; $\bar{M}_{n}=$ number average molar mass; $\bar{M}_{w}=$ weight average molar mass; $\mathrm{t}=$ estimated value. 
the epoxidation level. In other words, the product R5D(2E), obtained from the latex with $16 \%$ epoxidation, presented a higher ratio between the intensities of these groups than did the products $\mathrm{R} 14 \mathrm{D}(8 \mathrm{E})$ and $\mathrm{R} 16 \mathrm{D}(9 \mathrm{E})$, obtained from latex with $29 \%$ and $26 \%$ epoxidation, respectively, suggesting greater efficiency of the degradation reaction with the latex having $16 \%$ epoxidation. This was not expected, but it can be related to the larger quantity of formic acid or hydrogen peroxide remaining in the $16 \%$ epoxidized latex. The epoxidation reactions of these materials differed regarding the $\mathrm{NR}_{\text {epoxidized }}: \mathrm{HCOOH}$ and $\mathrm{NR}_{\text {epoxidized }}: \mathrm{H}_{2} \mathrm{O}_{2}$ ratios, which were respectively 1:0.2 and 1:0.2 in reaction $2 \mathrm{E}, 1: 0.4$ and 1:0.2 in reaction $8 \mathrm{E}$, and 1:0.2 and 1:0.4 in reaction $9 \mathrm{E}$.

In general, the products from degradation with a larger quantity of $\mathrm{H}_{5} \mathrm{IO}_{6}$ presented band intensities characteristic of the carbonyl function, at around $1720 \mathrm{~cm}^{-1}$, greater in comparison with the $\mathrm{C}=\mathrm{C}$ absorption band of the isoprene unit at $1660 \mathrm{~cm}^{-1}$, a finding that is in accordance with the literature $^{[18]}$ and with the molar mass results (Table 3 ). This difference was more pronounced in the products of the degradation reactions conducted for longer intervals.

The degradation products of the latex were also characterized by ${ }^{13} \mathrm{C}-\mathrm{NMR}$ and ${ }^{1} \mathrm{H}-\mathrm{NMR}$. Figure 6 shows the spectra of $\mathrm{R} 7 \mathrm{D}(3 \mathrm{E})$, with the same characteristic peaks of PI from the original latex. The low-intensity peaks at $3.65 \mathrm{ppm}(\mathrm{A}), 2.69 \mathrm{ppm}$ (B) and in the region between $2.11 \mathrm{NS}$ $2.0 \mathrm{ppm}(\mathrm{C})$ in Figure $6 \mathrm{a}$ can be attributed to, respectively, hydrogens of the hydroxyl group, hydrogens adjacent to the epoxide ring, and hydrogens of the methyl and methylene groups adjacent to the carbonyl, present in the structure after the degradation reaction. This indicates that the chemical structure of the degraded material is composed of isoprene units, epoxidized units and terminal ketone and aldehyde groups, although there was no evidence of $\mathrm{H}$ related to the carbonyl of the aldehyde group with greater chemical shift.

The ${ }^{13} \mathrm{C}-\mathrm{NMR}$ spectrum (Figure $6 \mathrm{~b}$ ) also did not indicate the presence of carbonyl, suggesting that the products $\mathrm{R} 6 \mathrm{D}(3 \mathrm{E})$ and $\mathrm{R} 7 \mathrm{D}(3 \mathrm{E})$ degraded inefficiently. This is in agreement with the FTIR spectra, which contained a carbonyl band with intensity less than or equal to that of the isoprene band.
Some peaks were present at approximately $1.60 \mathrm{ppm}$ and $1.30 \mathrm{ppm}$ (D) (Figure 6a), which can be attributed to the hydrogens of the secondary, tertiary and primary carbons of the hydrocarbon chain, probably arising from reactive impurities, as also observed in the carbon spectrum (peaks with low intensity in the range from 25 to $35 \mathrm{ppm}$ ).

\subsection{Products from oligomerization of isoprene}

The reactions using butyllithium (BuLi) were conducted by the mass technique (R\#-M) and the reactions using benzoyl peroxide were conducted in a solution of toluene (R\#-T) or xylene (R\#-X), seeking to favor reduction of the molar mass due to the chain transfer by the solvent. In some cases, dodecyl mercaptan $\left(\mathrm{C}_{12} \mathrm{SH}\right)$ was used as chain transfer agent.

Table 4 presents the molar masses of the samples obtained under different reaction conditions. In general, higher polydispersion $\left(\overline{\boldsymbol{M}}_{\boldsymbol{w}} / \overline{\boldsymbol{M}}_{\boldsymbol{n}}\right)$ and higher values of $\overline{\boldsymbol{M}}_{\boldsymbol{w}}$ were observed in comparison with the products from degradation of NR.

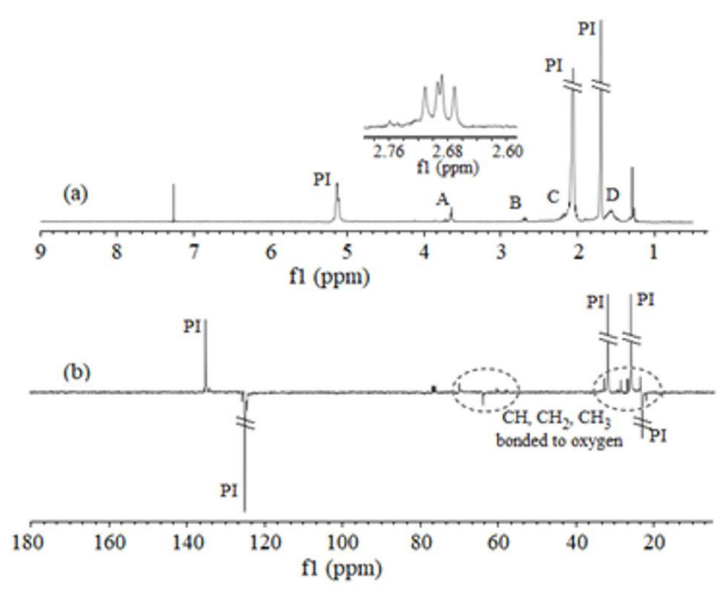

Figure 6. ${ }^{1} \mathrm{H}-\mathrm{NMR}(\mathrm{a})$ and ${ }^{13} \mathrm{C}-\mathrm{NMR}$ (b) spectra of R7D(3E), degraded latex products.

Table 4. Reaction conditions and respective molar masses of the products obtained from isoprene polimerization at $78^{\circ} \mathrm{C}$, after 48 hours.

\begin{tabular}{|c|c|c|c|c|c|c|c|}
\hline \multirow[t]{2}{*}{ Sample } & \multirow{2}{*}{$\begin{array}{c}{[\text { Iso] }} \\
(\mathrm{mol} / \mathrm{L})\end{array}$} & \multirow[t]{2}{*}{ Iso:Per } & \multirow{2}{*}{$\begin{array}{c}\text { Iso: } \\
\mathrm{C}_{12} \mathrm{SH}\end{array}$} & $\overline{\boldsymbol{M}}_{p}$ & $\bar{M}_{n}$ & $\overline{\boldsymbol{M}}_{w}$ & \multirow{2}{*}{$\bar{M}_{w} / \bar{M}_{n}$} \\
\hline & & & & & $(\mathrm{g} / \mathrm{mol})$ & & \\
\hline RP01-T & 6.7 & $1: 0.1$ & - & 3,072 & 2,857 & 10,179 & 3.56 \\
\hline RP02-T & 5.7 & $1: 0.3$ & - & 2,116 & 3,109 & 29,183 & 9.39 \\
\hline RP03-T & 5.0 & $1: 0.5$ & - & 15,488 & 18,512 & 90,069 & 4.86 \\
\hline RP04-X & 6.7 & 1:0.1 & - & 3,346 & 3,722 & 78,369 & 21.05 \\
\hline RP05-X & 5.7 & $1: 0.3$ & - & 2,926 & 2,712 & 10,797 & 3.98 \\
\hline RP06-X & 5.0 & $1: 0.5$ & - & 2,701 & 3,430 & 25,158 & 7.33 \\
\hline RP07-T & 1.3 & $1: 0.5$ & - & 2,327 & 2,109 & 13,490 & 6.39 \\
\hline RP08-T & 1.3 & 1:0.1 & - & 2,317 & 2,917 & 11,637 & 3.99 \\
\hline RP09-X & 1.3 & $1: 0.5$ & - & 2,636 & 2,550 & 8,786 & 3.45 \\
\hline RP10-X & 1.3 & 1:0.1 & - & 1,617 & 1,797 & 9,865 & 5.49 \\
\hline RP11-T & 6.7 & 1:0.1 & $1: 0.025$ & 3,119 & 2,431 & 9,968 & 4.10 \\
\hline RP12-X & 6.7 & $1: 0.1$ & $1: 0.025$ & 1,889 & 1,396 & 8,730 & 6.25 \\
\hline $\mathrm{R} 8-\mathrm{M}\left(30^{\circ} \mathrm{C} ; 1: 40 \mathrm{~h}\right)$ & (a) & $1: 0.16^{(\mathrm{b})}$ & - & 1,971 & 1,659 & 1,867 & 1.13 \\
\hline R14-M $\left(30^{\circ} \mathrm{C} ; 8 \mathrm{~h}\right)$ & (a) & $1: 0.16^{(\mathrm{b})}$ & 1:0.025 & 2,074 & 1,766 & 2,260 & 1.28 \\
\hline
\end{tabular}

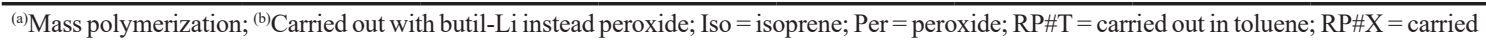
out in xylene. 
The reactions conducted with higher concentrations of isoprene ([Iso]) tended to generate products with larger molar masses. The smallest molar masses were obtained at an isoprene concentration of $1.3 \mathrm{~mol} / \mathrm{L}$. The monomer:initiator molar ratio that best promoted obtaining products with low molar masses was 1:0.1. This behavior was expected, because the presence of excess initiator can cause parallel reactions, which was revealed by FTIR for unreacted peroxide. With respect to the influence of the reaction solvents, the expected correlation was observed between molar mass and type of solvent: the lowest average molar masses were obtained from the reaction conducted with xylene, due to the higher chain transfer constant of this solvent in relation to toluene ${ }^{[11]}$.

The FTIR spectra FTIR (Figure 7) confirmed the reaction of isoprene by opening of the double bond, but due to the different reaction conditions, some absorption bands different to the bands of PI were identified. Figures $8 \mathrm{a}, 8 \mathrm{~b}$ and $8 \mathrm{c}$ show the FTIR spectra obtained, respectively, for the products R14-M, RP01-T and RP06-X, which represent the other products obtained in the same conditions, respectively, of anionic, free radical in toluene and free radical in xylene initiation.

The spectrum of the product R14-M (Figure 7a) was very similar to that of natural rubber, observing as well a band at approximately $840 \mathrm{~cm}^{-1}$ (A), which indicates the possibility that the product possessmolecules with cis isomerism. The absorption band at $3,700 \mathrm{~cm}^{-1}$ (B) can be related to the presence of isopropyl alcohol, utilized to stop the polymerization reaction. All the products obtained from the polymerization of isoprene with benzoyl peroxide presented spectra similar to those of the products RP01-T (Figure 7b) and RP06-X (Figure 7c). Particularly noteworthy was the presence of absorption bands in regions of lower frequency, generally attributed to the $\mathrm{C}=\mathrm{C}$ and $\mathrm{C}-\mathrm{H}$ vibrations

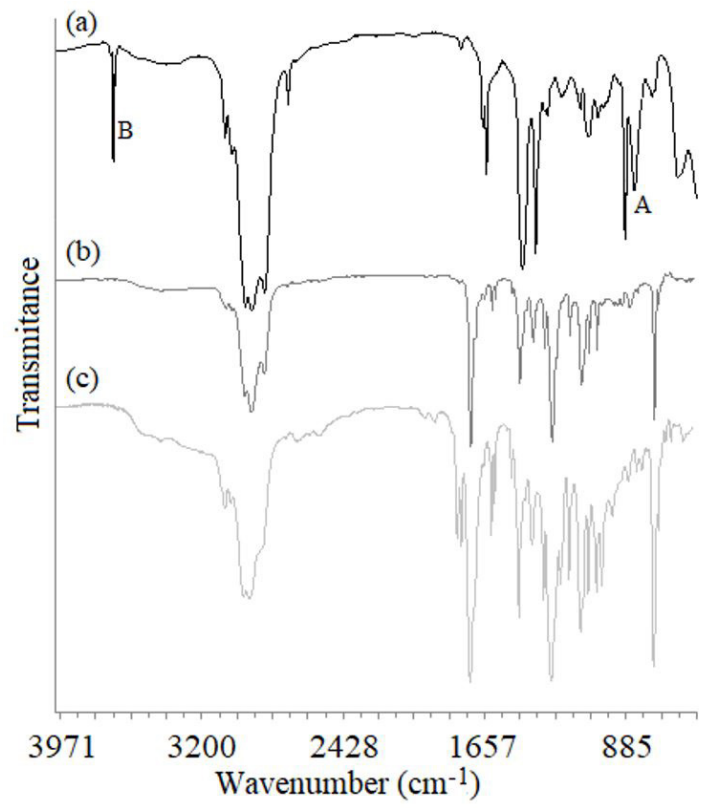

Figure 7. FTIR spectra of (a) R14-M, (b) RP01-T and (c) RP06-X products. of aromatic compounds, indicating the presence of residual solvent, besides the bands related to the chain's terminal peroxide group. The well-defined band at $1720 \mathrm{~cm}^{-1}$ can be attributed to the carbonyl derived from the peroxide. In RP06-X, there were two adjacent bands with equal intensity at $1789 \mathrm{~cm}^{-1}$ and $1767 \mathrm{~cm}^{-1}$, which can be related to the presence of residual benzoyl peroxide. The intensity of these bands increased as the peroxide concentration in the reaction increased, both in the reactions conducted in toluene and xylene. In other words, the concentration of benzoyl peroxide rose in the orders $\mathrm{RP} 01-\mathrm{T}<\mathrm{RP} 02-\mathrm{T}<\mathrm{RP} 03-\mathrm{T}$ and RP04-X $<\mathrm{RP} 05-\mathrm{X}<\mathrm{RP} 06-\mathrm{X}$, as did the intensities of the absorption bands referring to the $\mathrm{C}=\mathrm{O}$ coupled axial deformations

In the ${ }^{1} \mathrm{H}-\mathrm{NMR}$ spectra (Figure 8), characteristic peaks of hydrocarbon chains were observed in regions of low chemical shift ( $\sim 1.0$ to $3.0 \mathrm{ppm})$ (A), as well as two doublets corresponding to the hydrogens of terminal olefinic $\mathrm{CH}_{2}$, adjacent to the tertiary carbon probably present in the isoprene oligomers with low molar mass. These two doublets (B) were more evident in the samples obtained by mass polymerization. The samples obtained by solution polymerization contained residual solvent, revealed by the peaks in the chemical shift region between 7 and 9 ppm, which is characteristic of aromatic hydrocarbons.

A 3-factorial analysis was performed to evaluate the variables relevance and the confidence interval of actual molar mass from the three processes to obtain isoprene oligomers studied. Method (categorical) and, Reaction Temperature and Time (continuous) were considered the factors and $\bar{M}_{p}, \bar{M}_{n}, \bar{M}_{w}$ and $\bar{M}_{w} / \bar{M}_{n}$ (PD) the responses. The less significant interactions were removed from the effect summary. A log mathematical treatment could also be applied in molar mass data in order to improve the residual by predict plot. In general, the RSquare and RMSE values indicate an acceptable fit to the data and that the model was a good predictor of the response. The low PValues represent a higher confidence interval (95\%) of the prediction model. The greater significant factor to predict the response was Time and Temperature Interactions, while Method and its Interactions are less relevant as showed in Figure 9.

The mean and standard error values suggest that both methods of degradation were similar and provide polyisoprene with low molar mass as proposed. Greater standard error values were observed for the isoprene polymerization method, in comparison to the degradation methods, as showed in Table 5.

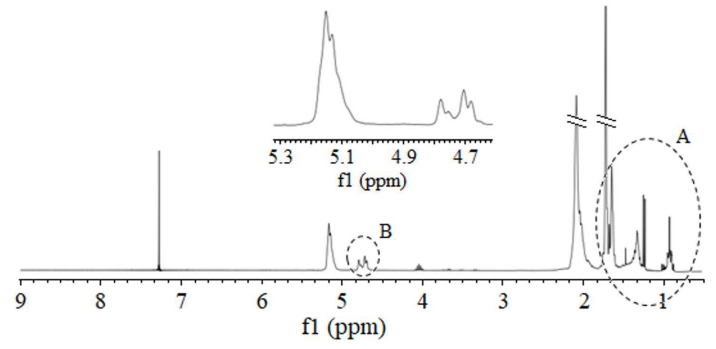

Figure 8. ${ }^{1} \mathrm{H}-\mathrm{NMR}$ spectrum of R10-M product. 
Effect Summary

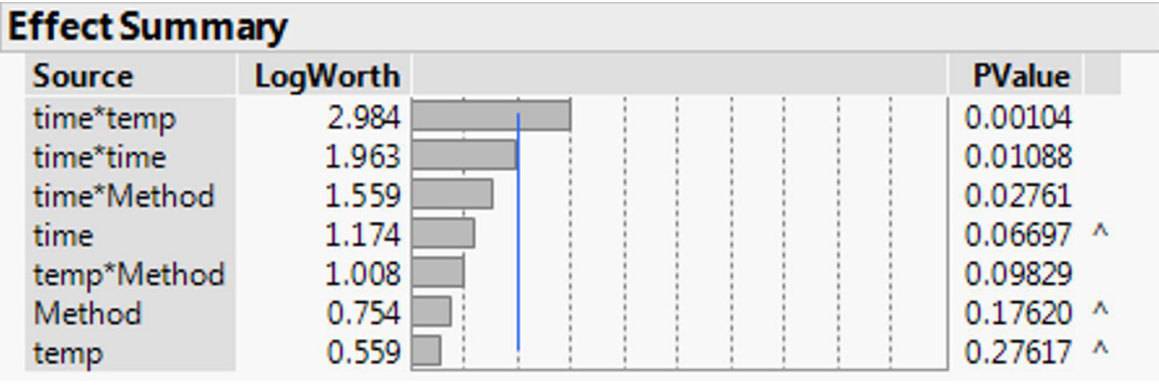

Figure 9. Effect summary obtained from JMP software.

Table 5. Standard error and mean of molar masses and polydispersion.

\begin{tabular}{|c|c|c|c|c|c|c|c|c|}
\hline \multirow[b]{2}{*}{ Method } & \multicolumn{4}{|c|}{ Standard error } & \multicolumn{4}{|c|}{ Mean } \\
\hline & $\bar{M}_{p}$ & $\bar{M}_{n}$ & $\overline{\boldsymbol{M}}_{\boldsymbol{w}}$ & PD & $\bar{M}_{p}$ & $\bar{M}_{n}$ & $\bar{M}_{w}$ & PD \\
\hline Coagulated NR degradation & 2,205 & 1,625 & 6,239 & 1.92 & 5,886 & 3,391 & 7,922 & 2.74 \\
\hline Latex degradation & 2,007 & 1,479 & 5,681 & 1.75 & 5,481 & 3,976 & 14,787 & 4.65 \\
\hline Isoprene olygomerization & 8,689 & 6,403 & 24,585 & 7.55 & 2,396 & 2,394 & 11,826 & 4.70 \\
\hline
\end{tabular}

$\bar{M}_{p}=$ molar mass at the peak of molar mass distribution curve; $\bar{M}_{n}=$ number average molar mass; $\bar{M}_{w}=$ weight average molar mass; PD = polydispersion.

\section{Conclusions}

The isoprene oligomerization, degradation of non-vulcanized coagulated natural rubber and degradation of natural rubber latex processes have satisfactorily produced isoprene oligomers, even that the reactions have been performed with different chemicals and reagents, and isoprene source. The molar mass can be somehow controlled in each process, for specific purposes. Reactions of isoprene with free radical initiation produced oligomers under specific conditions: low isoprene concentration, low initiator concentration, and xylene as solvent. However, the polydispersity of the products was relatively high. Isoprene oligomers with narrow molar mass distribution were easily obtained by anionic initiation. The mean and standard error values suggest that both methods of degradation (coagulated non-vulcanized and latex degradation reactions) were similar and provide polyisoprene with low molar mass as proposed. Greater standard error values were observed for the isoprene polymerization method, in comparison to the degradation methods. In this case, different experiment conditions were treated as a single factor, that is, the different mechanisms and technics of polymerization used, and also the solvent, are not distinctly evaluated in the categorical factor that represents the isoprene polymerization method. The degradation processes of natural rubber has as an advantage since this product comes from a renewable source, despite the relatively higher cost of the catalyst. However, the reaction with the coagulated non-vulcanized material led to purer products than those obtained from latex. Although the products have a similar main molecular structure, that is, polyisoprene based-chain, the functional end groups and lateral group from the three methods applied will differentiate the final products, providing varied hydrophilicity/hydrophobicity characteristic. This observation should be taken into account for material compatibility intended purpose, to use the isoprene oligomers.

\section{Acknowledgements}

The authors thank CNPq (307193/2016-0), CAPES (PVE \#1315110), FAPERJ (E-26/201.233/2014), ANP and Petrobras (0050.0069420.11.9) for financial support.

\section{References}

1. Magioli, M., Sirqueira, A. S., \& Soares, B. G. (2010). The effect of dynamic vulcanization on the mechanical, dynamic mechanical and fatigue properties of TPV based on polypropylene and ground tire rubber. Polymer Testing, 29(7), 840-848. http:// dx.doi.org/10.1016/j.polymertesting.2010.07.008.

2. Fainleib, A., Grigoryeva, O., Youssef, B., \& Saiter, J. M. (2011). Utilization of tire rubber and recycled polyolefins into thermoplastic elastomers. In A. Fainleib, \& O. Grigoryeva (Eds.), Recent developments in polymer recycling (pp. 1-46). Kerala: Transword Research Network.

3. Kébir, N., Campistron, I., Laguerre, A., Pilard, J.-F., \& Bunel, C. (2011). New crosslinked polyurethane elastomers with various physical properties from natural rubber derivatives. Journal of Applied Polymer Science, 122(3), 1677-1687. http:// dx.doi.org/10.1002/app.34013.

4. Roberts, A. D. (1988). Natural rubber science and technology. Oxford: Oxford University Press.

5. Wang, J., Hamed, G. R., Umetsu, K., \& Roland, C. M. (2005). The payne effect in double network elastomers. Rubber Chemistry and Technology, 78(1), 76-83. http://dx.doi. org/10.5254/1.3547874.

6. Brostow, W., \& Lobland, H. E. H. (2017). Materials introduction and applications. New Jersey: John Wiley \& Sons.

7. Fainleib, A., Pires, R. V., Lucas, E. F., \& Soares, B. G. (2013). Degradation of non-vulcanized natural rubber - renewable resource for fine chemicals used in polymer synthesis. Polimeros: Ciência e Tecnologia, 23(4), 441-450. http://dx.doi. org/10.4322/polimeros.2013.070.

8. Hesham, A. E.-L., Mohamed, N. H., Ismail, M. A., \& Shoreit, A. A. M. (2015). Degradation of natural rubber latex by new Streptomyces labedae strain ASU-03 isolated from Egyptian 
soil. Microbiology, 84(3), 351-358. http://dx.doi.org/10.1134/ S0026261715030078.

9. Polymer Properties Database. (2015). Thermal-oxidative degradation of rubber. Retrieved in 2018, May 30, from http:// polymerdatabase.com/polymer $\% 20$ chemistry/Thermal $\% 20$ Degradation\%20Elastomers.html

10. Ibrahim, S., Othman, N., \& Ismail, H. (2016). Degradation of natural rubber latex. In J. L. Hamilton (Ed.), Natural rubber: properties, behavior and applications (pp. 105-136). New York: Nova Science Publishers.

11. Odian, G. (2004). Principles of polymerization. New Jersey: John Wiley \& Sons. http://dx.doi.org/10.1002/047147875X.

12. Cowie, J. M. G., \& Arrighi, V. (2007). Polymers: chemistry and physics of modern materials. Boca Raton: CRC Press. http://dx.doi.org/10.1201/9781420009873.

13. Gutiérrez, S., Vargas, S. M., \& Tlenkopatchev, M. A. (2004). Computational study of metathesis degradation of rubber. distributions of products for the ethenolysis of 1,4-polyisoprene. Polymer Degradation \& Stability, 83(1), 149-156. http://dx.doi. org/10.1016/S0141-3910(03)00247-7.

14. Gutiérrez, S., \& Tlenkopatchev, M. A. (2011). Metathesis of renewable products: degradation of natural rubber via crossmetathesis with $\beta$-pinene using Ru-alkylidene catalysts. Polymer Bulletin, 66(8), 1029-1038. http://dx.doi.org/10.1007/ s00289-010-0330-x.

15. Grubbs, R. H. (2003). Handbook of metathesis. Weinheim: Wiley-VCH. http://dx.doi.org/10.1002/9783527619481.
16. Grubbs, R. H. (2007). Realizing the promise of olefin metathesis. Advanced Synthesis \& Catalysis, 349(1-2), 23-24. http://dx.doi. org/10.1002/adsc.200600621.

17. Gillier-Ritoit, S., Reyx, D., Campistron, I., Laguerre, A., \& Pal Singh, R. (2003). Telechelic cis-1,4-oligoisoprenes through the selective oxidolysis of epoxidized monomer units and polyisoprenic monomer units in cis-1,4-polyisoprenes. Journal of Applied Polymer Science, 87(1), 42-46. http:// dx.doi.org/10.1002/app.11661.

18. Phinyocheep, P., Phetphaisit, C. W., Derouet, D., Campistron, I., \& Brosse, J. C. (2005). Chemical degradation of epoxidized natural rubber using periodic acid: preparation of epoxidized liquid natural rubber. Journal of Applied Polymer Science, 95(1), 6-15. http://dx.doi.org/10.1002/app.20812.

19. Pilard, J. F., Saetung, A., Rungvichaniwat, A., Campistron, I., Klinpituksa, P., Laguerre, A., Phinyocheep, P., \& Doutres, O. (2010). Preparation and physico-mechanical, thermal and acoustic properties of flexible polyurethane foams based on hydroxytelechelic natural rubber. Journal of Applied Polymer Science, 117(2), 1279-1289. http://dx.doi.org/10.1002/app.31601.

20. Silverstein, R. M., Webster, F. X., \& Kiemle, D. J. (2005). Spectrometric identification of organic compounds. New Jersey: John Wiley \& Sons.

Received: June 14, 2018 Revised: Aug. 31, 2018 Accepted: Jan. 30, 2019 